\title{
openheart 'Paracelcus' rediscovered: searching for the right dose of physical training
}

\author{
Christian Schmied
}

To cite: Schmied C. 'Paracelcus' rediscovered: searching for the right dose of physical training. Open Heart 2014;1:e000027. doi:10.1136/openhrt-2013000027

Accepted 5 February 2014

CrossMark

\section{S Linked}

- http://dx.doi.org/10.1136 openhrt-2013-000005

Clinic of Cardiology, University Heart Center, Zurich, Switzerland

Correspondence to Dr Christian Schmied; christian.schmied@usz.ch
'All things are poison and nothing is without poison, only the dose makes a thing not a poison'.

When Phillipus Aureolus Theofrastus Bombastus von Hohenheim-better known as 'Paracelsus'-a Swiss German Renaissance physician, botanist, astrologer and philosopher coined this well-known quote about 500 years ago, he might not have thought about dose-dependent 'toxic' effects of regular sport. Nevertheless, these words perfectly fit a highly debated hot topic in sports cardiology: where is the upper limit of 'healthy' physical exercise and up from which 'dose' it might be even harmful?

Although quite much is known about the minimal efforts of physical exercise that have to be provided to gain health benefits, so far no 'upper limit' has been defined. ${ }^{1}$ However, adverse longtime effects of regular strenuous endurance training (eg, in cross-country skiers and bicycle racers) could be defined: as such, a multitude of studies proved an increased rate of atrial fibrillation in endurance athletes at an older age compared with age-matched controls. ${ }^{2}{ }^{3}$ The underlying morphological substrates are miscellaneous, consisting of inflammation, fibrosis and cavity dilation (figure 1 ). ${ }^{3}$

Another important 'weak spot', particularly in ambitious endurance athletes' hearts, is the right ventricle. As such, postrace dilation and decreased function of the right ventricle have been demonstrated impressively in cyclists, recently. ${ }^{4}$ Moreover, these changes are regressive but it might take a few weeks or months for the right ventricle to regain its primary function.

Thus, the border between acute and chronic adaptations caused by regular (endurance) training have become indistinct and should be interpreted as a 'grey zone'.

\section{ACUTE ADAPTATIONS ON PHYSICAL EFFORTS —DOES THE DOSE REALLY MATTER?}

Marathon races, nowadays, have become mass events, where many of the competitors face a physical burden they are by far not sufficiently prepared for. The fact that the average finishing times of nearly all of the large city marathons increased continuously in the past years reflects this behaviour; recently, marathon running has become a 'grassroots sport' (figure 2).

This situation reflects an extreme discrepancy between the sedentarity of a better part of the population on one side and extreme physical efforts of a growing subgroup on the other side. As a relevant part of the population competes at marathon events, these athletes have been in the focus of various surveys conducted recently; although marathon runners show a relevant postrace increase of cardiac biomarkers (eg, troponin I, troponin T, B-type natriuretic peptide), sometimes associated with transient dilation of the right atrium and particularly of the right ventricle and reduction of right ventricular ejection fraction, cardiovascular MRI suggests that this is not a result of serious ischaemic or inflammatory injury to any cardiac chamber. ${ }^{56}$

Not only after the 'RACER' study, a large survey in North-American marathon runners, that demonstrated a decreased risk for sudden cardiac arrest within the first half of a marathon run compared to the second half, the debate is going on whether halfmarathon harbours a justifiable risk for sportive individuals. ${ }^{7}$ In this issue of the journal, Dalla Vecchia and colleagues highlight the effects of half-marathon running on amateur athletes to add data to that particular subgroup performing at a relatively moderate level. Therefore, they enrolled a relatively small number of amateur athletes (at the age of $42 \pm 7$ years). Their findings could mostly be anticipated, however, the authors could demonstrate related (transient) changes that have been observed in marathon runners. ${ }^{5} 68$

Yet another unsolved issue is the question which individuals are particularly prone to acute structural, functional or biochemical response to high physical efforts: in a current 
Figure 1 The 'Triangle of Coumel' illustrating the interplay between different factors that promote and preserve atrial fibrillation, particularly in an athlete (adapted from Mont et $\left.a \beta^{\beta}\right)$.

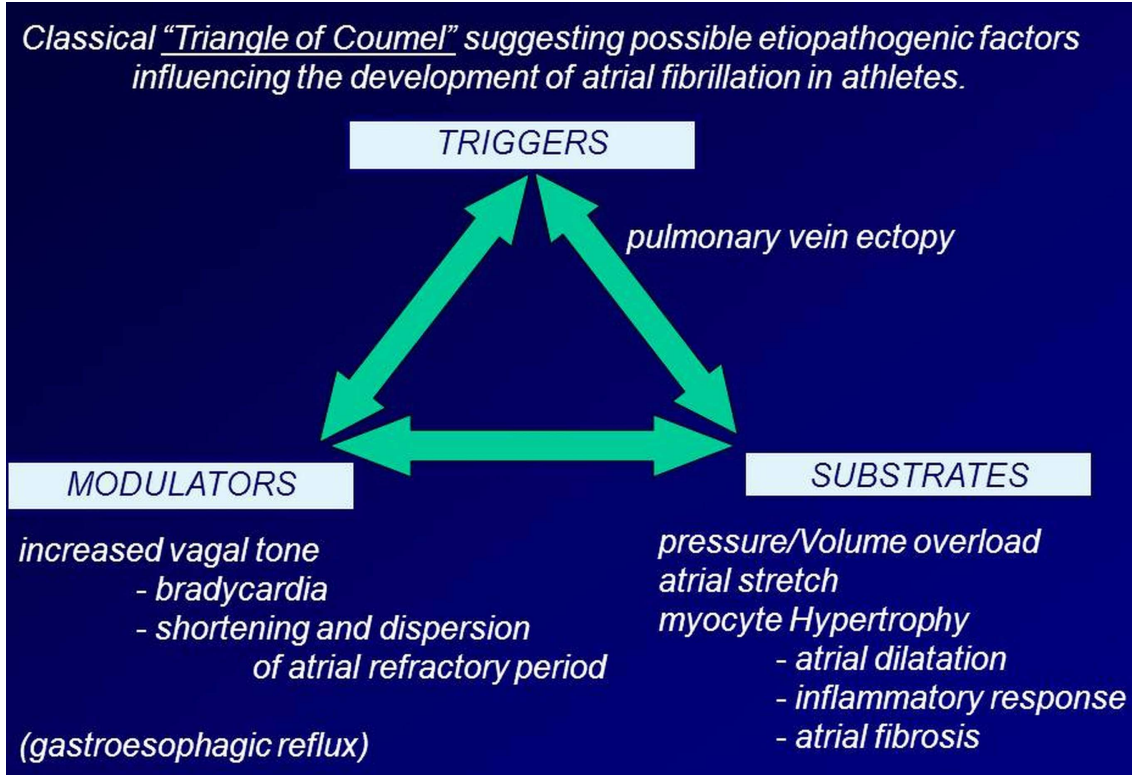

meta-analysis including 16 studies of 939 marathon runners with elevated postrace troponin-T (cTn) levels, the pooled OR for converting from a normal prerace to an elevated postrace cTn was 51.84 (95\% CI 16 to 168 , $\left.\mathrm{I}^{2}=66 \%, \mathrm{p}<0.001\right) .^{8}$

\section{CHRONIC ADAPTATIONS ON PHYSICAL EFFORTS- CLASSICAL 'CARDIAC FATIGUE' VERSUS 'ADVERSE REMODELLING'}

Multiple studies have pointed out increases in cardiac troponin and natriuretic peptides, as well as left and right ventricular dysfunctionality following an intense prolonged exercise. The term 'cardiac 'fatigue' has often been used to express relatively prompt and,

\begin{tabular}{|l|l|l|}
\hline year & finishers & average finishing time \\
\hline $\mathbf{2 0 0 0}$ & 27,870 & $04: 21: 46$ \\
\hline $\mathbf{2 0 0 1}$ & 28,390 & $04: 19: 28$ \\
\hline $\mathbf{2 0 0 2}$ & 31,093 & $04: 19: 51$ \\
\hline $\mathbf{2 0 0 3}$ & 32,395 & $04: 25: 09$ \\
\hline $\mathbf{2 0 0 4}$ & 33,033 & $04: 26: 53$ \\
\hline $\mathbf{2 0 0 5}$ & 32,995 & $04: 26: 22$ \\
\hline $\mathbf{2 0 0 6}$ & 33,618 & $04: 25: 02$ \\
\hline $\mathbf{2 0 0 7}$ & 28,815 & $04: 52: 11$ \\
\hline $\mathbf{2 0 0 8}$ & 31,343 & $04: 46: 30$ \\
\hline $\mathbf{2 0 0 9}$ & 33,475 & $04: 27: 20$ \\
\hline $\mathbf{2 0 1 0}$ & 36,159 & $04: 43: 48$ \\
\hline $\mathbf{2 0 1 1}$ & 35,670 & $04: 40: 34$ \\
\hline $\mathbf{2 0 1 2}$ & 37,455 & $04: 32: 02$ \\
\hline
\end{tabular}

Figure 2 Number of finishers and average finishing times at the Chicago marathon from the year 2000 to 2012 (source: 'Marathon Guide: Chicago Marathon'. MarathonGuide. 2012. Retrieved 9 October 2012). particularly, complete cardiac recovery. However, as aforementioned, the cut-off between acute and chronic cardiac adaptations lies within a grey-zone, particularly if focusing on right ventricular function that is more frequently and more profoundly affected. Moderate right ventricular dysfunction has been demonstrated using various imaging techniques. ${ }^{4}{ }^{6}$ However, the reason for this preponderance of right ventricular impairment is still unclear and it raises the hypothesis that repeated insults could explain a chronic right ventricular injury triggering potentially fatal arrhythmias.

Benito et $a l^{9}$ demonstrated another aspect of sustained intensive exercise in an animal model: "Ultra marathon rats' were conditioned to run vigorously for 4,8 and 16 weeks. Compared with their matched sedentary antipodes, the 'marathon rats' developed eccentric hypertrophy and diastolic dysfunction, together with atrial dilation. Furthermore, they demonstrated collagen deposition in the right ventricle. Messenger RNA and protein expression of fibrosis markers in the atria and right ventricle were significantly greater than in sedentary rats at 16 weeks. In $42 \%$ of the 'marathon rats,' ventricular tachycardia could be induced (significantly more than in sedentary rats). Moreover, the fibrotic changes provoked by 16 weeks of intensive exercise appeared reverse after an 8-week exercise cessation. Although these mechanisms need to be confirmed in humans-this study supports the hypothesis that longterm (repetitive) vigorous endurance training may lead to 'adverse cardiac remodelling' which leads to impairment and increased arrhythmic inducibility.

\section{ARE GENETICS THE KEY?}

Not only the results of the study with 'marathon rats' implicate that there is still an individual risk for acute and chronic adaptations to physical training that is most 
likely independent from the physical burden (within a certain range). ${ }^{9}$ In this context, it will be crucial to gain further data in the field of genetic susceptibility of an individual. A recent small study highlighted a possible role of microRNAs. ${ }^{10}$ Mooren et al could demonstrate that these crucial intracellular mediators, that also affect the cardiovascular system, significantly increase after a marathon race. Moreover, none of the microRNAs correlated with cardiac injury markers such as troponin $\mathrm{T}$, troponin I and pro-BNP. Probably, these muscle and heart-specific microRNAs not only have a potential role as biomarkers of aerobic capacity but also as markers for cardiac adaptations and even for the individual cardiac risk in athletes. ${ }^{10}$

Thus, at the bottom line, what would be of real impact is the question whether regular training (and competition) of an individual who performs on a relatively moderate level (eg, as half-marathon racers) provokes less longtime adverse effects on the athlete's heart.

However, to answer this question, randomised studies in larger cohorts are needed that observe not only acute, but long-time, effects of regular physical training at different levels.

Finally, the crucial question that asks for the perfect dose of physical activity still remains unanswered, but it will be-with the help of an individually tailored and adapted recommendation based on well-established and further developed tools as cardiopulmonary exercise tests and imaging techniques combined with genetic analysis. However, as this aim is still far from clinical practice, it completes the circuit-bringing me back to another famous 'Paracelsus' quote:

'Dreams must be heeded and accepted. For a great many of them come true.'
Competing interests None.

Provenance and peer review Commissioned; internally peer reviewed.

Open Access This is an Open Access article distributed in accordance with the Creative Commons Attribution Non Commercial (CC BY-NC 3.0) license, which permits others to distribute, remix, adapt, build upon this work noncommercially, and license their derivative works on different terms, provided the original work is properly cited and the use is non-commercial. See: http:// creativecommons.org/licenses/by-nc/3.0/

\section{REFERENCES}

1. Fletcher GF, Balady G, Blair SN, et al. Statement on exercise: benefits and recommendations for physical activity programs for all Americans. A statement for health professionals by the Committee on Exercise and Cardiac Rehabilitation of the Council on Clinical Cardiology, American Heart Association. Circulation 1996;94:857-62.

2. Elosua R, Arquer A, Mont L, et al. Sport practice and the risk of lone atrial fibrillation: a case-control study. Int J Cardiol 2006;108:332-7.

3. Mont L, Elosua R, Brugada J. Endurance sport practice as a risk factor for atrial fibrillation and atrial flutter. Europace 2009;11:11-17.

4. La Gerche A, Burns AT, Mooney DJ, et al. Exercise-induced right ventricular dysfunction and structural remodelling in endurance athletes. Eur Heart J 2012;33:998-1006.

5. Trivax JE, Franklin BA, Goldstein JA, et al. Acute cardiac effects of marathon running. J Appl Physiol 2010;108:1148-53.

6. O'Hanlon R, Wilson M, Wage R, et al. Troponin release following endurance exercise: is inflammation the cause? A cardiovascular magnetic resonance study. J Cardiovasc Magn Reson 2010;12:38.

7. Kim JH, Malhotra R, Chiampas $\mathrm{G}$, et al. Cardiac arrest during long-distance running races. N Engl J Med 2012;366:130-4.

8. Regwan $\mathrm{S}$, Hulten EA, Martinho $\mathrm{S}$, et al. Marathon running as a cause of troponin elevation: a systematic review and meta-analysis. J Interv Cardiol 2010;23:443-50.

9. Benito B, Gay-Jordi G, Serrano-Mollar A, et al. Cardiac arrhythmogenic remodeling in a rat model of long-term intensive exercise training. Circulation 2011;123:13-22.

10. Mooren FC, Viereck J, Krüger K, et al. Circulating microRNAs as potential biomarkers of aerobic exercise capacity. Am J Physiol Heart Circ Physiol 2014;306:H557-63. 